\begin{tabular}{|l|l|l||}
\hline \multicolumn{2}{|c|}{ PublisherInfo } \\
\hline \hline PublisherName & $:$ & BioMed Central \\
\hline \hline PublisherLocation & $:$ & London \\
\hline \hline PublisherImprintName & $:$ & BioMed Central \\
\hline \hline
\end{tabular}

\title{
Mammographic screening does not result in a reduction in breast cancer mortality when added to annual clinical breast examinations
}

\begin{tabular}{|l|l|l||}
\hline \multicolumn{2}{|c|}{ ArticleInfo } \\
\hline \hline ArticleID & $:$ & 3738 \\
\hline \hline ArticleDOI & $:$ & $10.1186 /$ bcr-2000-66701 \\
\hline \hline ArticleCitationID & $:$ & 66701 \\
\hline \hline ArticleSequenceNumber & $:$ & 104 \\
\hline \hline ArticleCategory & $:$ & Paper Report \\
\hline \hline ArticleFirstPage & $:$ & 1 \\
\hline \hline ArticleLastPage & $:$ & 4 \\
\hline \hline & & RegistrationDate : 2000-10-9 $\quad: \quad 2000-10-9$ \\
\hline ArticleHistory & $:$ & OnlineDate \\
\hline \hline ArticleCopyright & $:$ & Current Science Ltd2000 \\
\hline \hline ArticleGrants & $:$ & \\
\hline \hline ArticleContext & $:$ & 1305822 \\
\hline \hline
\end{tabular}


David Cameron, ${ }^{\text {Aff1 }}$

Affl Western General Hospital, Edinburgh, UK

\section{Keywords}

Breast screening, mammography, mortality, randomised trial, survival

\section{Introduction}

Regular physical examination has traditionally been thought to have little role in breast cancer screening, with most of the positive randomised trials using mammography as the screening modality. However the true survival benefit of even mammographic screening has recently been questioned.

\section{Aims}

To compare breast cancer mortality following annual screening by two-view mammography and physical examination with screening by physical examination only.

\section{Comments}

Since this study challenges the established standards of routine breast cancer screening, it is tempting to look for its faults and leave the established approach unquestioned. The American College of Radiology (ACR) notes that mammograms were read by radiologists with no specific training in mammography (see Additional information). One could consider this study as evidence that substandard mammographic screening does not add to well-taught physical screening in terms of a survival benefit. This could be an important conclusion for health planners in areas where provision of high-quality mammographic screening is difficult.It is interesting to compare these data with the 14-year follow-up from the Edinburgh trial, which randomised a larger number of women, to either a similar combination of mammography and annual breast self-examination or no screening intervention. The breast cancer death rates were generally higher in the Edinburgh study. A major difference between the two studies 
was that the Edinburgh study was population based, whereas the Canadian (CNBSS-2) study was volunteer based, and may therefore be an inaccurate representation of the effect of population based screening. Furthermore, the difference in breast cancer mortality between the similar screening-arms of the two studies suggests that despite a higher incidence of cancer in the Canadian women, the cancers diagnosed had a better prognosis. Thus, since the end-point of the study was breast cancer mortality, the Canadian study was under-powered to detect the degree of mortality reduction seen in the Edinburgh study.CNBSS-2 does not provide evidence to undermine the current mammographic screening paradigm, but is consistent with the notion that in the absence of supplementary high-quality mammographic screening, regular good clinical examination may be important in the early detection of invasive breast cancer. An even larger study is required to produce a definitive answer.

\section{Methods}

Volunteer-based randomised trial of regular breast physical examination plus or minus regular mammography.

\section{Results}

There was a clear increase in the detection of invasive breast cancer in the combined physical examination plus mammography group. During the screening rounds, 267 invasive cancers were found by mammography with physical examination compared with 148 detected by physical examination only. However the mortality rates, both breast-cancer specific and overall, were the same for the two groups. During the 13 year follow-up the difference in detection almost disappeared with 622 invasive and $71 \mathrm{in}$ situ cancers detected by mammography with physical examination and 610 invasive and 16 in situ detected by physical examination only.

\section{Discussion}

The authors refute the accusations from the ACR about the quality of some of the early mammograms, and point out that mammographic screening had no effect on the incidence of nodepositive breast cancers. They liken this lead time effect without benefit to that of a similar unpublished observation in lung cancer, and suggest that earlier diagnosis of more advanced cancers by physical examination resulted in a survival advantage that was not further improved upon by the earlier mammographic detection of much lower risk cancers. 


\section{Additional information}

American\%20College\%20of\%20Radiology criticisms of this study.

Edinburgh trial reports:

Alexander FE, Anderson TJ, Brown HK, Forrest AP, Hepburn W, Kirkpatrick AE, Muir BB, Prescott RJ, Smith A:14 years of follow-up from the Edinburgh randomised trial of breast-cancer screening. Lancet 1999, 353:1903-1908 (PubMed\%20abstract)

\section{References}

1. Miller AB, To T, Baines CJ, Wall C: Canadian national breast screening study-2: 13-year results of a randomized trial in women aged 50-59 years. J Natl Cancer Inst. 2000, 92: 1490-1499.

This PDF file was created after publication. 